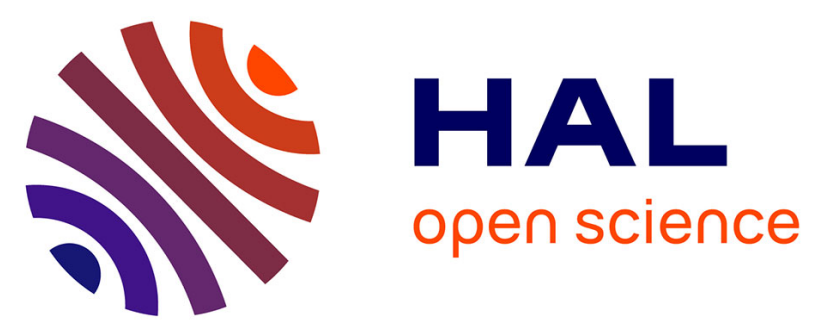

\title{
REFLECTION-ABSORPTION IR SPECTROSCOPY AS AN IN-SITU PROBE OF THE SURFACE CHEMISTRY OF SEMICONDUCTOR GROWTH INTERMEDIATES : THE ADSORPTION OF TRIMETHYLGALLIUM AT GaAs (100) SURFACES AT $300 \mathrm{~K}$ \\ H. Patel, M. Pemble
}

\section{- To cite this version:}

H. Patel, M. Pemble. REFLECTION-ABSORPTION IR SPECTROSCOPY AS AN IN-SITU PROBE OF THE SURFACE CHEMISTRY OF SEMICONDUCTOR GROWTH INTERMEDIATES : THE ADSORPTION OF TRIMETHYLGALLIUM AT GaAs (100) SURFACES AT $300 \mathrm{~K}$. Journal de Physique IV Proceedings, 1991, 02 (C2), pp.C2-167-C2-173. 10.1051/jp4:1991220 • jpa-00249807

HAL Id: jpa-00249807 https://hal.science/jpa-00249807

Submitted on 1 Jan 1991

HAL is a multi-disciplinary open access archive for the deposit and dissemination of scientific research documents, whether they are published or not. The documents may come from teaching and research institutions in France or abroad, or from public or private research centers.
L'archive ouverte pluridisciplinaire HAL, est destinée au dépôt et à la diffusion de documents scientifiques de niveau recherche, publiés ou non, émanant des établissements d'enseignement et de recherche français ou étrangers, des laboratoires publics ou privés. 
JOURNAL DE PHYSIQUE IV

Colloque C2, suppl. au Journal de Physique II, Vol. 1, septembre 1991

\begin{abstract}
REFLECTION-ABSORPTION IR SPECTROSCOPY AS AN IN-SITU PROBE OF THE SURFACE CHEMISTRY OF SEMICONDUCTOR GROWTH INTERMEDIATES : THE ADSORPTION OF TRIMETHYLGALLIUM AT GAAS (100) SURFACES AT $300 \mathrm{~K}$
\end{abstract}

\author{
H. PATEL and M.E. PEMBLE \\ Department of Chemistry and Centre for Electronic Materials, \\ University of Manchester. Institute of Science and Technology, \\ P.O. Box 88, Sackvilie St, GB-Manchester M60 1QD, \\ Great-Britain
}

\begin{abstract}
FTIR spectroscopy has been used in reflection-absorption mode to monitor the adsorption of trimethylgallium (TMGa) at GaAs (100) surfaces at $300 \mathrm{~K}$. Intense, positive going transmittance bands are observed, which confirm the theoretical prediction that the presence of an adsorbate layer at a semiconducting substrate which itself does not absorb the IR radiation, will result in a net increase in absolute $\mathbb{R}$ reflectivity. Three bands are observed in the $\mathrm{CH}$ deformation region, at $1050 \mathrm{~cm}^{-1}, 1174$ $\mathrm{cm}^{-1}$ and $1420 \mathrm{~cm}^{-1}$. The latter two bands are shown to be consistent with the formation of a surface species in which the methyl groups are intact, although lack of data in the Ga-C region prevents an unambiguous assignment. These band positions together with their spectral intensities are shown to be consistent with the formation of a physisorbed TMGa species. However, the band at $1050 \mathrm{~cm}^{-1}$ is not consistent with this assignment. Some alternative modes of adsorption are discussed in the light of data for TMGa adsorption at Si surfaces.
\end{abstract}

The data presented here are the first external reflection IR data available for possible III-V growth surface intermediates at GaAs (100) surfaces and indicate the potential of the reflection-absorption method for the detection of adsorbed species under real MOVPE and related growth conditions.

\title{
INTRODUCTION
}

The need for a greater understanding of the surface chemistry involved in the MOVPE growth of compound semiconductors such as GaAs has lead to the development of several photon-based methods which are able to provide information specific to the substrate surface and also bridge the 'pressure gap' that exists for conventional surface science methods. Of these methods, reflectance anisotropy (RA) [1-3] and optical second harmonic generation (SHG) [4-6] seem to be the most popular at the present time. These and related methods employ first and second order variations in surface reflectivity respectively and, while capable of providing kinetic information, are not in the first instance truly spectroscopic in that the data cannot be used to identify specific surface intermediates. In contrast, surface IR spectroscopy is capable of providing direct information as to the vibrations of adsorbed species, which permits the complete structural characterisation of such species and has the added advantage in being applicable over a wide pressure regime unlike the conventional surface science method of recording surface vibrational spectra, electron energy loss spectroscopy (EELS). However, while used successfully in other areas of surface science [7,8], the application of IR techniques to the study of semiconductor surfaces is not trivial. For Si surfaces, attenuated total (internal) reflection (ATR) spectroscopy has been used very successfully by Chabal and coworkers to obtain good quality surface spectra $[9,10]$. This method, which utilises the substrate as the internal reflection element, involves perhaps 50-100 internal reflections of the IR radiation within the substrate resulting in the ability to detect of fractions (1\%) of a monolayer of adsorbed species. This method of 
sampling has also been exploited by Joseph, Hicks, Sadwick and Wang for the detection of adsorbed hydrogen atoms on As-terminated MBE-grown GaAs $(100)[11,12]$ and the detection of buried C-H units following the growth of $\mathrm{GaAs}$ from trimethylgallium (TMGa) [12,13]. While being capable of producing good quality spectra, this method is not appropriate for the in-situ study of any growing surfaces since as Chesters has pointed out, at elevated temperatures $(>600-700 \mathrm{~K})$ free carrier absorption will prevent the transmission of the IR radiation through the substrate [14].

The alternative approach of a single pass transmission experiment in which the IR beam is incident on the substrate at near the Brewster angle may result in an improvement in signal-to-noise of perhaps 1030 as compared to a single external reflection [14], although this method is again limited to relatively low temperature studies by free carrier absorption.

In contrast to sampling methods in which the radiation passes through the substrate, external reflection should not, in theory be limited by free carrier absorption and would thus seem an attractive approach yet this mode of sampling is believed to be severely limited by expected signal levels. For this method of sampling, which is used extensively in the study of adsorbed species on metal single crystal

surfaces [8], Chesters has predicted that the absolute change in IR reflectivity $(\Delta R)$ as measured for the p-component of the IR radiation that would be expected for a system comprising a monolayer of an adsorbate with a moderate absorption coefficient, $(n=1, k=0.1)$, of thickness $5 \AA$, adsorbed at a silicon surface reaches a maximum of $5 \times 10^{-5}$ at an angle of around 85 degrees, and furthermore is positive, [14], in marked contrast to the behaviour noted for adsorbates on metallic substrates [7]. This arises from the lack of absorption by the substrate in the IR region, $(\mathrm{k}=0)$. Coupled with the variation in total reflectivity, this gives rise to an expected change in relative reflectivity $(\Delta R / R)$ of around $10^{-4}$, such that overall positive going transmittance bands on the order of $0.01-0.1 \%$ may be expected dependent upon the value of $\mathrm{k}$ for the adsorbate [14]. For the adsorption of hydrogen atoms at $\mathrm{a} \mathrm{Si}$ (111) surface Chesters has confirmed this prediction, observing a positive going band in a transmittance spectrum recorded as a ratio of single beam spectra from the adsorbate covered and clean surfaces near $2100 \mathrm{~cm}^{-1}$, having an intensity of $0.05 \%$ transmittance, which was assigned to an $\mathrm{Si}-\mathrm{H}$ stretching mode by comparison with the work of Chabal et al. [10]. This change in relative reflectivity is of the opposite sign and on the order of $20 \mathrm{x}$ less than that expected for adsorbates on metallic surfaces where there is an enhancement of the electric vector of the p-component of the incident radiation near grazing incidence as a consequence of the strong absorption of the radiation by the metal (typically $k=30$ ) [7]. The consequent experimental difficulties associated with such low signal levels were illustrated by the data of Chesters which showed that for the particular experimental system employed, a band of $0.05 \%$ transmittance was only just discernible above the inherent noise levels.

Thus it is clear that at least for the study of Si surfaces, the external reflection-absorption IR experiment is possible, although the expected signal levels are close to the limit of detectability using conventional instrumentation.

Since GaAs has almost the same optical constants as $\mathrm{Si}$ in the IR region, i.e. $n=3.0, k=0$, we have examined the feasibility of the external reflection-absorption method as an in-situ probe of GaAs MOVPE growth surface processes. In this paper we present what are believed to be among the first examples of external surface reflection-absorption IR spectra obtained from a compound semiconductor surface, for the adsorption of TMGa on GaAs (100) at $300 \mathrm{~K}$. Good quality, high signal-to-noise spectra have been obtained which most likely correspond to multilayer formation which is believed to occur at $300 \mathrm{~K}$ [15], which demonstrate the potential of this technique as an in-situ surface probe for MOVPE growth studies.

\section{EXPERIMENTAL}

The experimental arrangement used in this work is shown in figure 1. A Biorad FTS-40v FTIR spectrometer fitted with a narrow band $\left(800-3000 \mathrm{~cm}^{-1}\right)$, liquid nitrogen cooled mercury cadmium telluride detector was used in conjunction with a reflection cell connected to a gas handling system. Substrates were n-type GaAs (100), Si doped to $1 \times 10^{17} \mathrm{~cm}^{-3}$, of surface area approximately $2 \mathrm{~cm}^{2}$ (MCP Electronics). The reflection cell could be evacuated to pressures of $10^{-8}$ mbar using a combination liquid nitrogen trapped diffusion pump and rotary pump. 


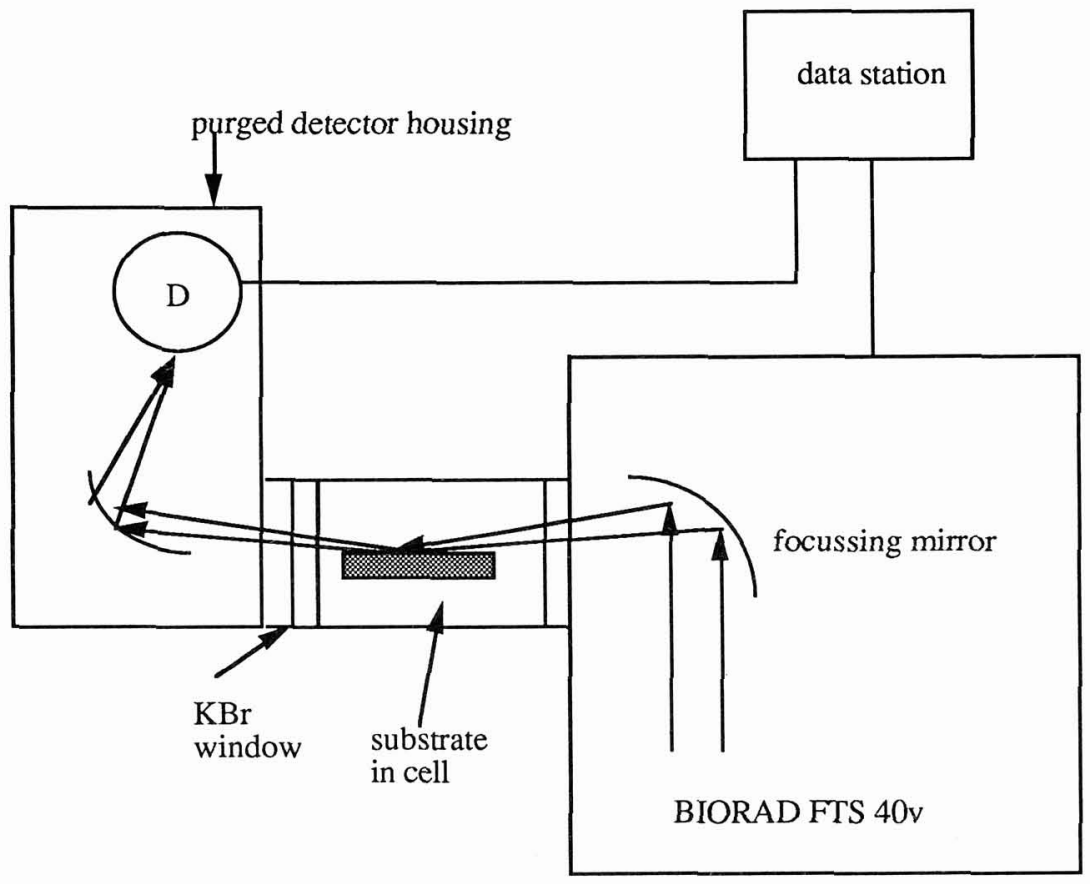

Figure 1. Experimental arrangement for reflection-absorption IR measurements

\section{RESULTS AND DISCUSSION}

Figure 2 depicts a transmittance spectrum recorded from the GaAs (100) surface following exposure to approximately $10^{5}$ Langmuirs TMGa at $300 \mathrm{~K}$ (where 1 Langmuir $(\mathrm{L})=1 \times 10^{-6}$ torr. sec). The background (clean surface) spectrum used to obtain these data was recorded following annealing the substrate in $10^{-3}$ mbar $\mathrm{H}_{2}$ at $770 \mathrm{~K}$ for some 10 minutes, which is believed to result in a clean surface, nominally gallium rich [16]. The clean surface and adsorbate covered spectra were recorded at a spectral resolution of $8 \mathrm{~cm}^{-1}$, averaging over 1000 scans over a period of approximately 5 minutes. It should be noted that the time required to obtain the spectrum depicted in figure 2 is at least comparable to the time required to obtain an EEL spectrum, yet the spectral resolution of the reflection IR technique is far superior to that currently attainable by EELS. Figure 2 depicts the spectral region where C-H deformation modes normally occur. The $\mathrm{Ga}-\mathrm{C}$ region, and the $\mathrm{C}-\mathrm{H}$ region were not accessible to these experiments owing to the limited range of the detector employed. From figure 2, it can be seen that adsorption of TMGa on GaAs (100) at $300 \mathrm{~K}$ gives rise to at least three bands in the C-H deformation region, at 1420,1174 and $1050 \mathrm{~cm}^{-1}$. Note in particular the intensities of the bands, which range from 4-10\% transmittance. These are discussed in more detail later. 


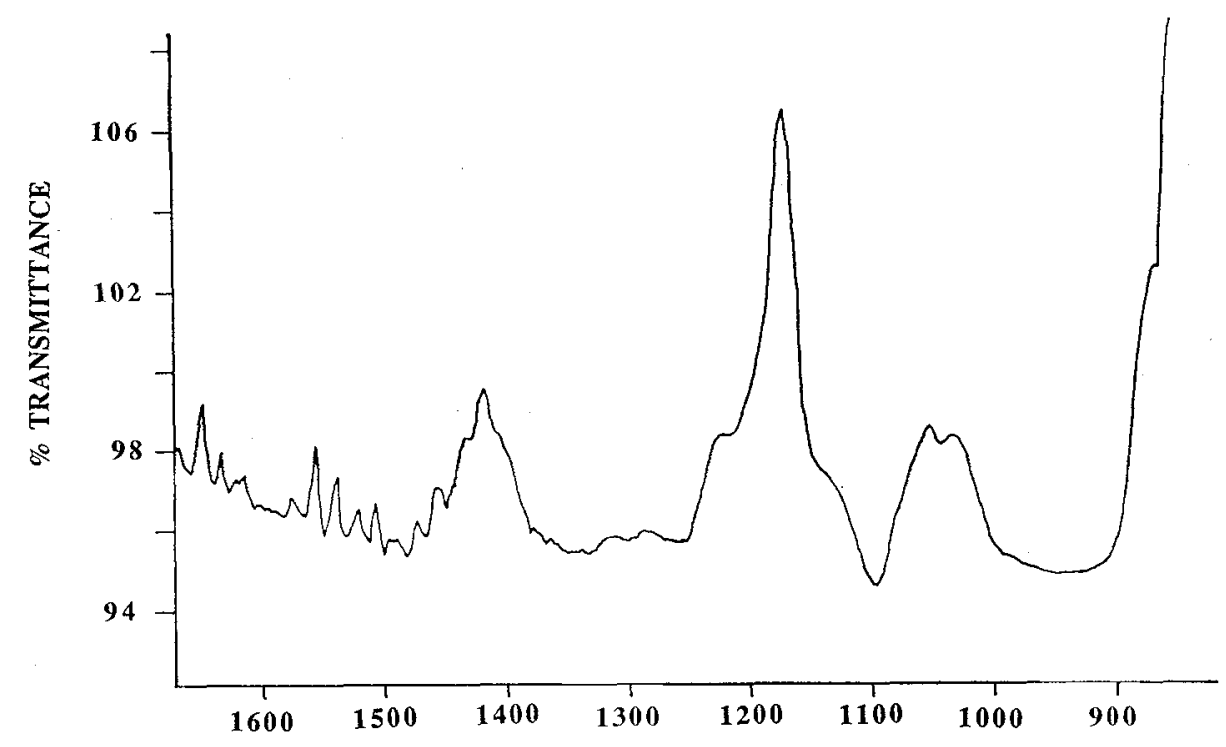

WAVENUMBER $/ \mathrm{cm}^{-1}$

Figure 2. Transmittance reflection-absorption IR spectrum recorded from a GaAs (100) surface following exposure to approximately $10^{5} \mathrm{~L}$ TMGa at $300 \mathrm{~K}$, ratioed to a clean surface spectrum obtained after annealing in $\mathrm{H}_{2}$ at $770 \mathrm{~K}$, see text.

In terms of band assignments, some data are available from other surface chemical studies of TMGa adsorption. Luth and coworkers [17] and Lee et al. [18] have studied the adsorption of TMGa on Si surfaces at $300 \mathrm{~K}$ using EELS, detecting bands in the region $1200-1500 \mathrm{~cm}^{-1}$ which they assign to $\mathrm{C}-\mathrm{H}$ deformations of molecularly adsorbed TMGa. These studies were also able to detect loss features assigned to $\mathrm{Ga}-\mathrm{C}$ vibrations near $524 \mathrm{~cm}^{-1}$, further supporting the concept of molecular adsorption as described below:

In the gas phase, TMGa gives rise to IR absorptions at $570-590 \mathrm{~cm}^{-1}$ assigned to the Ga-C asymmetric stretch, $770 \mathrm{~cm}^{-1}$ assigned to a $\mathrm{CH}_{3}$ rock, $1200-1211 \mathrm{~cm}^{-1}$ assigned to a symmetric $\mathrm{CH}_{3}$ deformation, $1400 \mathrm{~cm}^{-1}$ assigned to an asymmetric $\mathrm{CH}_{3}$ deformation, combination bands in the region $1700-2900 \mathrm{~cm}^{-1}$ and $3000 \mathrm{~cm}^{-1}$ assigned to a $\mathrm{C}-\mathrm{H}$ asymmetric stretch [19]. These assignments are based upon the adoption of a planar molecular geometry such that the molecule is described by the point group $\mathrm{D}_{3 \mathrm{~h}}$. Adsorbed at a surface, the point group will be altered reflecting a lowering of the molecular symmetry. For example, if the TMGa molecule remains intact and adsorbs at the GaAs (100) surface via the $\mathrm{Ga}$ atom then the point group for the combined molecule-surface complex will be $\mathrm{C}_{3 \mathrm{v}}$. One consequence of this is that the symmetric $\mathrm{Ga}-\mathrm{C}$ stretch will become IR active due to the lack of inversion symmetry within the complex. In the gas phase this mode is IR inactive but data from Raman studies of liquid TMGa place this mode at $521 \mathrm{~cm}^{-1}$ [19]. Thus it is clear that for TMGa adsorption on $\mathrm{Si}(111)$ at $300 \mathrm{~K}$, the proposals of Luth and Lee et al. that molecular adsorption occurs seems very reasonable.

With these data in mind, a possible explanation for the spectrum shown in figure 2 is that the TMGa molecule also remains intact upon adsorption at a Ga-rich $\mathrm{GaAs}(100)$ surface at $300 \mathrm{~K}$, giving rise to bands at 1174 and $1420 \mathrm{~cm}^{-1}$ representing the symmetric and asymmetric $\mathrm{CH}_{3}$ deformations respectively. However, this assignment does not account for the band at $1050 \mathrm{~cm}^{-1}$. The wavenumber position of this mode suggests that it would be in the correct place to be an overtone of the symmetric 
Ga-C stretching mode. This is not felt to be a likely explanation since firstly the intensity of this band is comparable with that of the other two bands where an overtone might be expected to be considerably weaker, and secondly, that no comparable loss features were noted in the EELS spectrum of molecular TMGa on Si (111). Nonetheless, the proposal that the spectrum shown in figure 2 corresponds to molecularly adsorbed TMGa is strongly supported by the band intensities, which are too high to be accounted for by the presence of a single monolayer.

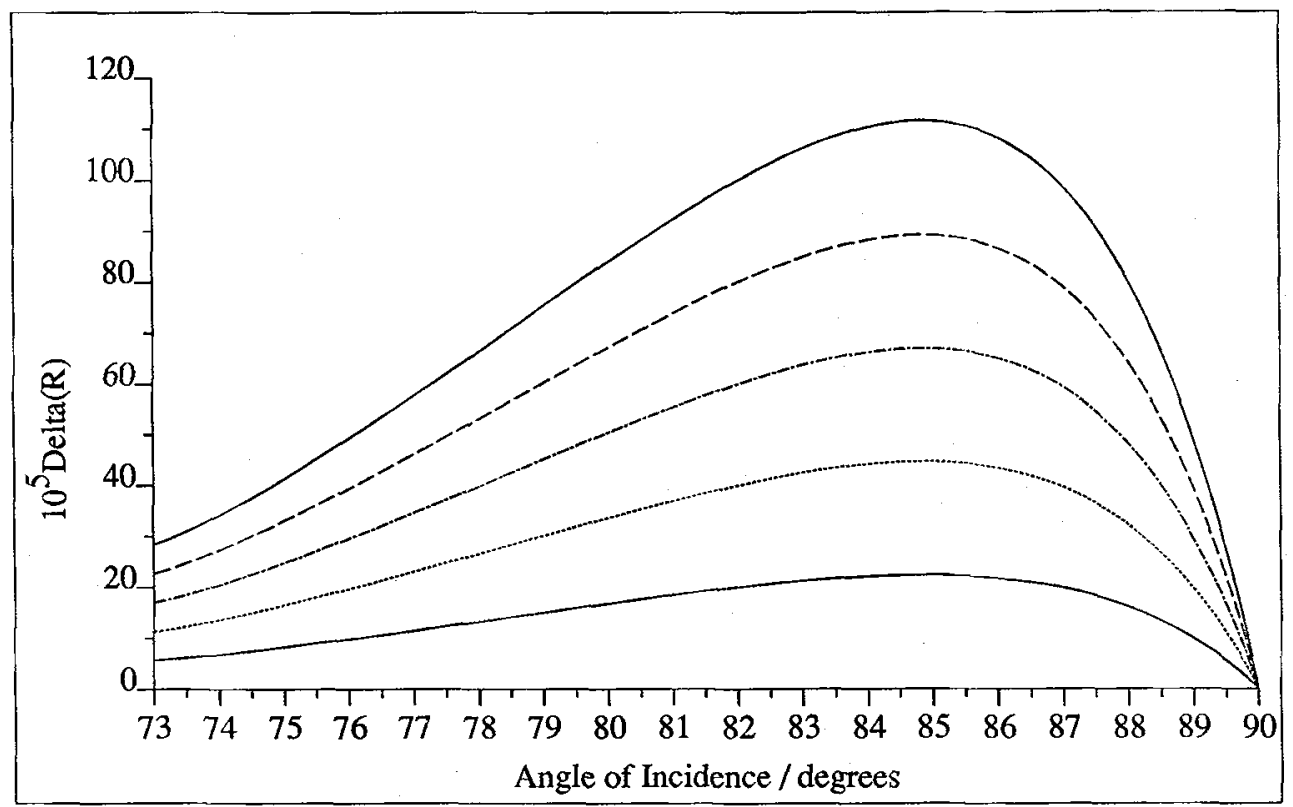

Figure 3. Variation in absolute reflectivity as calculated at $1500 \mathrm{~cm}^{-1}$, for a GaAs substrate $(n=3.0, k=0)$, covered with a moderately absorbing film of an adsorbate $(n=1.3, k=0.5)$ as a function of increasing film thickness.

This is illustrated by the data shown in figure 3. Figure 3 depicts the variation in absolute reflectivity for a GaAs substrate at the optimum angle of incidence of 85 degrees, as a function of increasing layer thickness, as calculated using the equations for p-polarised light given by McIntyre and Aspnes [20] and typical parameters for a moderately absorbing film.

The equations of McIntyre and Aspnes reveal that the absolute reflectivity is linearly dependent upon film thickness $[20]$. The trace corresponding to a $5 \AA$ thick layer is the same as that calculated by Chesters as noted earlier for the Si (111) system with the exception that $\mathrm{k}$ has been taken as 0.5 , rather than 0.1 in recognition of the fact that at least from gas-phase data; TMGa is a moderately strong IR absorber. Increasing the film thickness from $5 \AA$ to $25 \AA$ will obviously result in an increase in the absolute change in reflectivity of a factor of 5 which, in comparison with Chesters data for only a moderate absorber $(k=0.1)$ generates an overall increase in absolute reflectivity of $>20$. Therefore, these data support the proposal that multilayers of TMGa adsorbed at a GaAs (100) surface will generate positive transmittance IR bands that are relatively intense, i.e. of comparable intensity (in \% transmittance units) to those observed for monolayers of only moderate IR absorbers on metallic surfaces.

Thus it may be concluded that the intensities of the bands depicted in figure 2 may not be anomalous, but rather are consistent with the formation of multilayers of a moderate to strong IR absorber. The major uncertainty in these calculations at the present time arises from the uncertainty in $\mathrm{k}$ for adsorbed TMGa. We are currently performing measurements to accurately measure the value of $k$ for gas-phase TMGa which, assuming that the TMGa is only physisorbed, will enable us to determine the approximate number of adsorbed layers suggested from the data depicted in figure 2 , and hence allow 
us to estimate the potential of the reflection IR method for the detection of monolayer or sub-monolayer amounts of adsorbates.

The question as to the origin of the band at $1050 \mathrm{~cm}^{-1}$ remains. A possible answer lies in the exploration of alternative models for TMGa adsorption. In particular, three possibilities should be considered:

(1) It is quite possible that TMGa adsorption on GaAs (100) at $300 \mathrm{~K}$ occurs dissociatively. This view is supported by previous XPS data that were interpreted as being indicative of dissociative TMGa adsorption on a Ga-rich GaAs (100) surface at $300 \mathrm{~K}$ [21]. The chemical nature of the dissociated form of TMGa was not discussed in this work, but the implication was that the methyl groups remain intact although very little data were presented to support this proposal. Auger studies performed in our laboratories also support the proposal that the hybridisation of the surface carbons remains essentially $\mathrm{sp}^{3}$ and that no net loss of carbon-containing species occurs upon adsorption at a Ga-rich GaAs (100) surface at $300 \mathrm{~K}$ [15]. In view of this it is possible that the band at $1050 \mathrm{~cm}^{-1}$ arises from the formation of $\mathrm{C}-\mathrm{C}$ bonds via reactions of adsorbed methyl groups. Obviously more data are required in order to test this proposal, but this assignment would be consistent with the fact that TMGa decomposition on GaAs (100) surfaces results in high levels of surface carbon [22].

(2) For TMGa adsorption on Si surfaces intramolecular reactions have been reported, albeit at temperatures greater than $300 \mathrm{~K}$ [18], which are said to involve hydrogen abstraction by one methyl group from another to produce $\mathrm{CH}_{2}$ and ultimately $\mathrm{CH}$ surface groups. Using EELS, Lee et al. observe this hydrogen abstraction to occur at temperatures of between $400-600 \mathrm{~K}$ on Si (111), giving rise to loss features at 950 and $1520 \mathrm{~cm}^{-1}$ which these workers have assigned to vibrations of a $\mathrm{CH}_{2}$ unit [18]. Again it is possible that similar reactions occur on GaAs (100) surfaces such that the 1050 $\mathrm{cm}^{-1}$ band arises from a deformation mode of a strongly bound $\mathrm{CH}_{\mathrm{X}}$ unit.

(3) Surface and/or background gas contamination may induce reactions involving unknown species, which give rise to species responsible for the band in question.

Consideration of these three possibilities immediately indicates the necessity of obtaining IR spectra in the region $400-800 \mathrm{~cm}^{-1}$ since these should reflect any chemical changes that occur in the nature of the $\mathrm{Ga}-\mathrm{C}$ bonds. At the present time we are unable to make any comments as to which of these alternative pathways, (if any), apply to the data shown in figure 2 . However, the intensity of the band at 1050 $\mathrm{cm}^{-1}$ is found to vary often quite dramatically between similar experiments suggesting that possibility (3) is quite likely to play some part in generating the species responsible for this band.

\section{CONCLUSIONS}

We have demonstrated for the first time that reflection-absorption IR spectroscopy may be used to detect an adlayer of a typical semiconductor growth precursor TMGa, adsorbed at a GaAs (100) substrate. High quality spectra have been obtained in a relatively short data aquisition period using a resolution which is far superior to that available using EELS. Comparison of the data with data for liquid and gaseous TMGa and for TMGa adsorbed at Si surfaces and an analysis of likely band intensities suggests that TMGa adsorption on GaAs (100) surfaces at $300 \mathrm{~K}$ occurs molecularly and generates multilayers, although this assignment does not account for all of the IR data suggesting that the true situation may be more complex. Further experimentation is required before any unambiguous comment may be made. The implications of this work are that reflection IR methods may be used to study growing surfaces under pseudo 'steady state' conditions, particularly where higher pressures are employed such as in MOVPE growth, since here it is likely that there will be several layers of precursor reacting at the substrate surface at any given instant.

\section{ACKNOWLEDGEMENTS}

The support of the SERC for both equipment and an earmarked studentship for HP is gratefully acknowledged. 


\section{REFERENCES}

1 D E Aspnes, J P Harbison. A A Studna and L T Florez, Phys. Rev. Lett., 59, (1987), 1687.

2 D E Apnes, A A Studna, L T Florez, Y C Chang, J P Harbison, M K Kelly and H H Farrell, J. Vac. Sci. Tech., B7, (1989), 901.

3 L Samuelson, K Deppert, S Jeppesen, J Jonsson, G Paulsson and P Schmidt, J. Crystal Growth, 107, (1991), 68.

4 J F McGilp, J. Phys. Condensed Matter, 2, (1990), 7985.

5 D S Buhaenko, S M Francis, P A Goulding and M E Pemble, J. Crystal Growth, 97, (1989), 595.

6 M E Pemble, J T Allen, D S Buhaenko, S M Francis, P A Goulding, J Lee and M J Parrott, Appl. Surface Sci., 46, (1990), 32.

7 For the theory of RAIRS as developed for adsorbates on metal surfaces, see R G Greenler, J. Chem. Phys., 44, (1966), 310 and J. Vac. Sci. Tech., A12, (1975), 1410.

8 M A Chesters, Reflection-Absorption Infrared Spectroscopy of Adsorbates on Metal Surfaces, in 'Analytical Applications of Spectroscopy', Eds. C S Creaser and A M C Davies, Royal Society of Chemistry, London, 1988.

9 Y J Chabal and K Raghavachari, Phys. Rev. Lett., 53, (1984), 282.

10 Y J Chabal, Surface Science Reports, 8, (1988), 211.

11 D M Joseph, R F Hicks, L P Sadwick and K L Wang, Surface Science, 204, (1988), L721.

12 L P Sadwick, K L Wang, D L Joseph and R F Hicks, J. Vac. Sci. Tech., B7, (1989), 273.

13 D L Joseph, R Balagopal, R F Hicks, L P Sadwick and K L Wang, Appl. Phys. Lett., 53, (1988), 2203.

14 M A Chesters, A B Horn, E J C Kellar, S F Parker and R Raval, in 'Mechanisms of Reaction of Organometallic Compounds with Surfaces', Eds. D J Cole-Hamilton and J O Williams, NATO ASI Series, Series: B, Physics Vol. 198, Plenum; 1989.

15 D S Buhaenko and M E Pemble, submitted to J. Crystal Growth, Feb., 1991.

16 D S Buhaenko, S M Francis, P A Goulding and M E Pemble, J. Crystal Growth, 97, (1989), 591.

17 H Luth, J. Vac. Sci. Tech., A7, (1989), 696.

18 F Lee, T R Gow, R Lin, A L Backman, L A Cadwell and R I Masel, Vacuum,41, 1990, 951.

19 G E Coates and A J Downs, J. Chem. Soc., (1964), 3353.

20 J D E McIntyre and D E Aspnes, Surface Science, 24, (1971), 417

21 J A McCaulley, V R McCrary and V M Donnelly, J. Phys. Chem., 93, (1989), 1148.

22 D S Buhaenko and M E Pemble, J. Phys. Condensed Matter, in press. 